\title{
Technical feasibility of Impella Recover 100 microaxial left ventricular assist device placement after biologic aortic valve replacement $(21 \mathrm{~mm})$ for postcardiotomy failure
}

\author{
Justus T. Strauch, MD, Ulrich F. W. Franke, MD, Martin Breuer, MD, Jens Wippermann, MD, Thorsten Wittwer, MD, \\ Navid Madershahian, MD, Mirko Kaluza, and Thorsten Wahlers, MD, Jena, Germany
}

$\mathrm{T}$ he Impella Recover 100 (Impella CardioSystems AG, Aachen, Germany) is an intravascular microaxial blood pump intended to provide short-term mechanical support for acutely reduced left ventricular function in the setting of postcardiotomy heart failure refractory to high-dose inotropic support and intra-aortic balloon pump support. The lowcost device is fast to insert across the aortic valve through a $10-\mathrm{mm}$ vascular graft sewn to the ascending aorta, avoiding the use of cardiopulmonary bypass, is simple to remove, and is associated with good properties for weaning. ${ }^{1-3}$ However, the Impella has just recently been introduced into clinical practice, and no information is available about its use in patients who have previously undergone biologic aortic valve replacement, especially with small prosthesis sizes.

This report summarizes our initial clinical experience with such a patient. It should encourage the surgical community to take the device into consideration for borderline indications as a last resort.

\section{Clinical Summary}

A 69-year-old woman was admitted to our hospital after a diagnosis of coronary artery disease and severe aortic valve stenosis. The patient's history showed myocardial infarction of the anterior wall weeks previously, with multiple coronary artery interventions to the left anterior descending coronary artery, including stent implantation. In addition, aortic valve stenosis was diagnosed, with a peak-to-peak gradient of $61 \mathrm{~mm} \mathrm{Hg}$, an effective valve orifice area of $0.64 \mathrm{~cm}^{2}$, and left ventricular end-diastolic pressure of 30 $\mathrm{mm} \mathrm{Hg}$. Left ventricular ejection fraction was $25 \%$, and EuroSCORE at the time of the operation was 12 .

The patient underwent technically uneventful coronary artery revascularization with thoracic artery grafting to the left anterior descending coronary artery and aortic valve replacement with a 21 $\mathrm{mm}$ sized stented biological prosthesis. Weaning from cardiopul-

\footnotetext{
From the Department of Cardiothoracic and Vascular Surgery, FriedrichSchiller University, Jena, Germany.

Received for publication June 24, 2005; accepted for publication Aug 1, 2005.

Address for reprints: Justus T. Strauch, MD, Friedrich-Schiller University of Jena, Department of Cardiothoracic and Vascular Surgery, Erlanger Allee 101, D-07747 Jena, Germany (E-mail: justus.strauch@med.uni-jena.de).

J Thorac Cardiovasc Surg 2005; 130:1715-6

$0022-5223 / \$ 30.00$

Copyright $\odot 2005$ by The American Association for Thoracic Surgery

doi:10.1016/j.jtcvs.2005.08.005
}

monary bypass was accomplished with moderate catecholamine support. Shortly after coming off cardiopulmonary bypass, the patient had low cardiac output syndrome with an increase in left atrial pressure, decline of cardiac output, and an increased need for inotropic support. Subsequently, the patient underwent implantation of an intra-aortic balloon pump to control postcardiotomy failure. The patient's clinical condition deteriorated further, with a rise in inotropic support (epinephrine at $0.39 \mu \mathrm{g}$ / $[\mathrm{kg} \cdot \min ]$ and norepinephrine of $1.1 \mu \mathrm{g} /[\mathrm{kg} \cdot \mathrm{min}])$. We therefore considered further left ventricular support; however, we hesitated to insert an Impella left ventricular assist device because with a $21-\mathrm{mm}$ stented biologic valve it is said to be impractical to get through the biologic stented valve prosthesis. The pump body in its current existing form shows 7.3-mm diameter at the level of the outflow area located directly above the aortic valve area, and surgeons are commonly afraid of injuring the leaflet tissue of the valve.

After further impairment in the patient's condition, we decided to implant the Impella as final supportive therapy, after balancing all the pros and cons. After rethoracotomy, a 10-mm vascular graft was sewn to the ascending aorta (Figure 1). Without cardiopulmonary bypass, the device was inserted in a retrograde fashion across the stented aortic bioprosthesis from the ascending aorta into the cavity of the left ventricle. There were no technical difficulties regarding the previously described small orifice area of the 21-mm stented bioprosthesis for the device insertion. Under transesophageal echocardiographic guidance, only one attempt was necessary to get the device through the prosthesis (Figure 2). During the surgical procedure, transesophageal echocardiography played an essential role in the anatomic evaluation of the heart and correct intraventricular positioning of the device, ${ }^{4}$ as did the careful observation of the pressure-differential curve on the device control. Device implantation resulted in a flow of $4.9 \mathrm{~L} / \mathrm{min}$, and the patient's condition stabilized throughout the next 24 hours, with a decline in catecholamine support. The patient died 4 days later with signs of multiorgan failure resistant to therapy, dominated by liver failure with a missing neogenesis of glucose and a loss of coagulation.

\section{Discussion}

We encourage cardiac surgeons in the situation of critically ill patients in the setting of postcardiotomy heart failure, even after stented biologic aortic valve prosthesis implantation, to take the Impella Recover 100 device into consideration. We advise surgeons to embrace the use of this device as soon as possible for special borderline indications and not to waste any time in particularly life-threatening situations. 


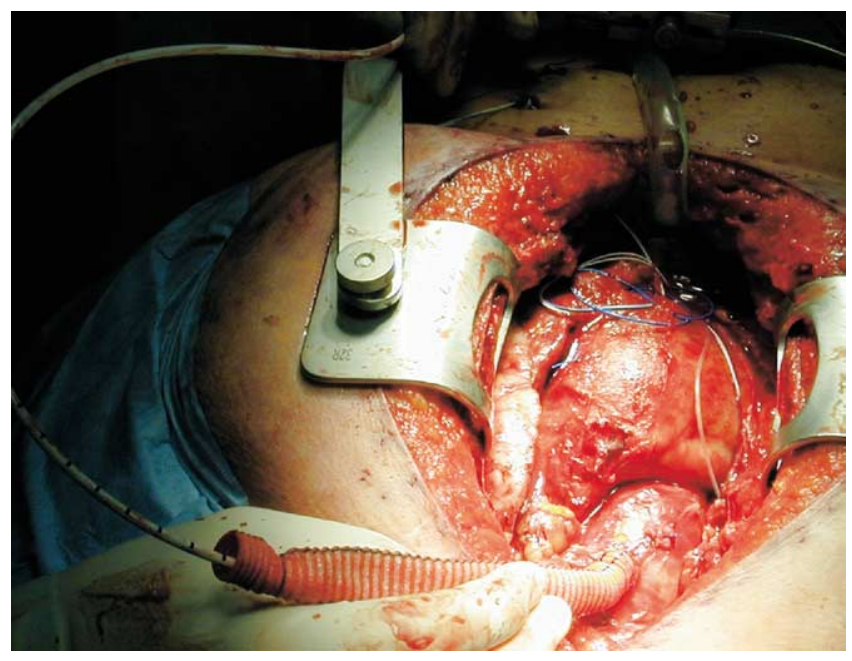

Figure 1. Impella Recover 100 device introduced in retrograde fashion into left ventricle through $10-\mathrm{mm}$ prosthetic graft sewn to ascending aorta.

\section{References}

1. Siegenthaler MP, Brehm K, Strecker T, Hanke T, Nötzold A, Olschewski M, et al. The Impella Recover microaxial left ventricular assist device reduces mortality for postcardiotomy failure: a three-center experience. J Thorac Cardiovasc Surg. 2004;127:812-22.

2. Garatti A, Colombo T, Russo C, Lanfranconi M, Milazzo F, Catena E, et al. Different applications for the left ventricular mechanical support

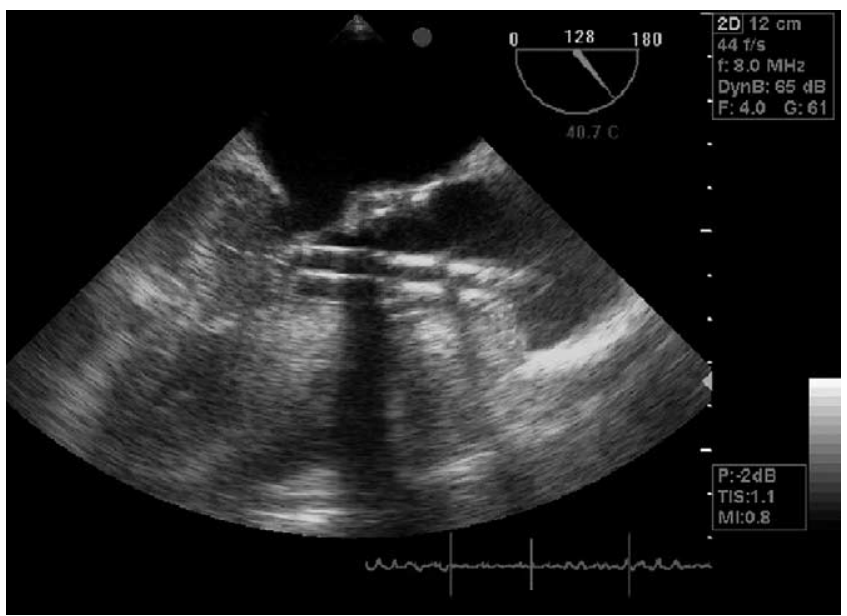

Figure 2. Intraoperative transesophageal echocardiographic guidance for correct intraventricular positioning of Impella Recover 100 across $21-\mathrm{mm}$ stented aortic bioprosthesis.

with the Impella Recover 100 microaxial blood pump. J Heart Lung Transplant. 2004;24:481-5.

3. Jurmann MJ, Siniawski H, Erb M, Drews T, Hetzer R. Initial experience with miniature axial flow ventricular assist devices for postcardiotomy heart failure. Ann Thorac Surg. 2004;77:1642-7.

4. Catena E, Milazzo F, Pittella G, Paino R, Colombo T, Garatti A, et al. Echocardiographic approach in a new left ventricular assist device: Impella Recover 100. J Am Soc Echocardiogr. 2004;17:470-3. 